
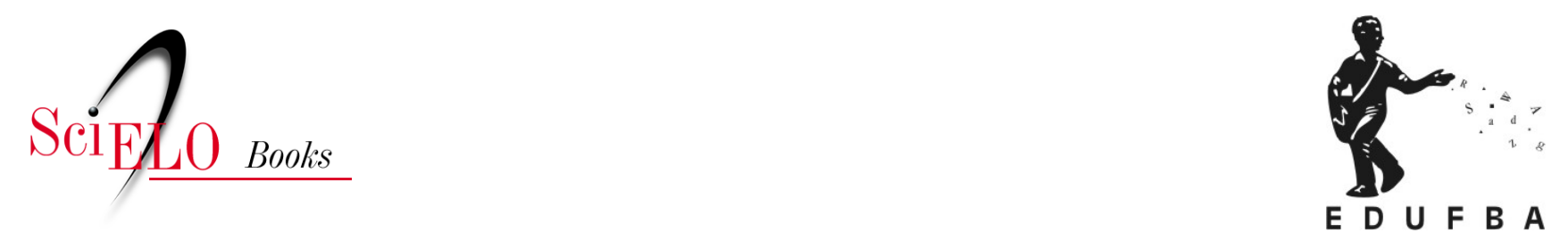

\title{
Capítulo 8 \\ Construindo continuidade frente a sucessivas rupturas: estratégias semióticas de reparação dinâmica do self
}

\author{
Vívian Volkmer Pontes
}

\section{SciELO Books / SciELO Livros / SciELO Libros}

PONTES, V.V. Construindo continuidade frente a sucessivas rupturas: estratégias semióticas de reparação dinâmica do self. In: Trajetórias interrompidas: perdas gestacionais, luto e reparação [online]. Salvador: EDUFBA, 2016, pp. 220-229. ISBN: 978-85-232-2009-9.

https://doi.org/10.7476/9788523220099.0010.

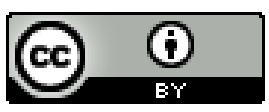

All the contents of this work, except where otherwise noted, is licensed under a Creative Commons Attribution 4.0 International license.

Todo o conteúdo deste trabalho, exceto quando houver ressalva, é publicado sob a licença Creative Commons Atribição $\underline{4.0}$. 
CAPÍTULO 8

Construindo continuidade frente a sucessivas rupturas: estratégias semióticas de reparação dinâmica do self 


\section{Perdas gestacionais involuntárias: descontinuidades no desenvolvimento do self}

A experiência de uma perda gestacional involuntária é entendida neste trabalho como ruptura, tanto no sentido da gestação em desenvolvimento, daquilo que se esperava e que estava na iminência de acontecer (o tornar-se mãe e o nascimento de um bebê), mas também no sentido de descontinuidade do desenvolvimento do self (entendimentos e expectativas que vinham sendo construídos acerca de si e do mundo). Deste modo, todo o sistema de significados que estava sendo construído sobre o curso da gravidez é bruscamente interrompido por sua não realização. Em outras palavras, a expectativa é violada pela ruptura e encerramento de uma trajetória que faz, por sua vez, iniciar outra, a da tentativa de elaboração de sentido da perda gestacional e o não tornar-se mãe de uma criança. Nesse sentido, argumenta-se que quando a trajetória de vida de uma pessoa sofre uma inesperada interrupção há a emergência de uma percepção ampliada de incerteza frente ao futuro e a intensificação da ambivalência - eventos que se configuram como ruptura, como descontinuidade no sistema do self. Com efeito, a experiência recorrente deste tipo de ruptura significativa exige processos constantes de reposicionamento do self a fim de melhor entender e dar sentido ao ocorrido.

Durante períodos de transição no desenvolvimento humano - como quando alguém está tentando reparar e resolver uma ruptura existencial -, faz-se necessária a construção de algum significado pessoal de modo a investir simbolicamente a pessoa de poder, permitindo-lhe reassumir o controle sobre sua narrativa pessoal, que frequentemente torna-se caótica e incerta devido à constante exposição às perdas gestacionais e seus efeitos psicologicamente angustiantes. Isto possibilita a redefinição da 
identidade, envolvendo a construção e a mobilização da representação de si mesmo no passado e de possíveis "selves" no futuro, em um determinado contexto sociocultural. (Zittoun, 2004)

Com o propósito de construir um senso de continuidade, de integridade e consistência através da experiência de rupturas recorrentes ao longo da trajetória de vida, dá-se uma busca psicológica de autopreservação do self dessas mulheres - por meio do que denominei estratégias semióticas de reparação dinâmica do self. Tais estratégias ao serem utilizadas, levam à construção de signos específicos - os signos reparadores -, que operam sobre os fragmentos da trajetória interrompida, promovendo algum tipo de articulação entre esses fragmentos, resgatando certo senso de continuidade.

Antes, porém, de aprofundar as noções conceituais relativas às estratégias semióticas de reparação dinâmica do selfe signo reparador, faz-se importante descrever e analisar a natureza específica das perdas gestacionais de repetição.

\section{A natureza das perdas gestacionais}

As rupturas ocasionadas por perdas gestacionais recorrentes apresentam algumas características particulares. Em primeiro lugar, abortos espontâneos são frequentemente considerados perdas ocultas, na medida em que são muitas vezes desconhecidos de outras pessoas ou não reconhecidos, considerados como não eventos. Nesse sentido, são rupturas que levam a transições não normativas (Cowan, 1991), isto é, transições não esperadas pessoal e socialmente. Com efeito, não contam com o suporte sociocultural no nível mesogenético da experiência. (Valsiner, 2012) Isto significa que tais experiências de perda não são guiadas pela estrutura mesogenética coletiva-cultural, ou seja, não sofrem a canalização dentro de contextos de atividade culturalmente estruturados, havendo a ausência, por exemplo, de rituais fúnebres, como o velório e o enterro - atividades que ajudariam à mulher e sua família a tornar a perda real, facilitando o processo de luto. Assim, sem 
o apoio no nível mesogenético da experiência, as perdas gestacionais têm um grande impacto sobre o nível ontogenético, isto é, sobre o desenvolvimento do indivíduo ao longo do seu ciclo de vida, representando uma ameaça à saúde mental da mulher.

Em segundo lugar, perdas gestacionais são eventos que interrompem acontecimentos importantes no sistema familiar: o desenvolvimento da gravidez, o nascimento de um bebê, o exercício da parentalidade. São rupturas no desenvolvimento de algo muito significativo, que envolve signos hipergeneralizados como maternidade, filiação e família - signos muitas vezes internalizados como valores pessoais (para além de valores socioculturais), que guiam e organizam a conduta, o pensamento e os afetos humanos. (Valsiner, 2012) Deste modo, configuram-se em experiências profundamente afetivas.

Por fim, as perdas gestacionais são eventos involuntários que se repetem ao longo das trajetórias reprodutivas de mulheres que persistem na tentativa de se tornarem mães, engravidando novamente a despeito dos riscos de uma possível nova perda. São rupturas recorrentes ao longo da trajetória de vida, que desafiam incessantemente a possibilidade de manutenção da posição Eu-mãe - posição do Eu relevante para essas mulheres -, a partir da perspectiva do self dialógico. (Hermans, 1996; Hermans \& Hermans-Jansen, 2003) Nesse sentido, tais rupturas exigem a confrontação repetida de aspectos importantes de suas identidades, como aqueles relacionados ao empoderamento feminino - ao poder da mulher relacionado à sua liberdade de decidir e controlar o seu próprio destino, da autonomia no que se refere ao controle do seu próprio corpo e da sua sexualidade.

\section{Estratégias semióticas de reparação dinâmica do self}

As estratégias semióticas de reparação dinâmica do self são a expressão de um esforço contínuo de autorregulação semiótica da mente, mediante eventos que provocam ruptura no sistema de significado pessoal-cultural, com a finalidade de manutenção da saúde psíquica 
do indivíduo. O processo de constituição das estratégias semióticas de reparação pode ser decomposto em três tempos, que ocorrem quase que simultaneamente:

Tempo 1: Há a ocorrência de um evento disruptivo irreparável, que rompe súbita e definitivamente o que era imaginado e esperado acontecer no futuro próximo ou imediato (ruptura temporal), como a ocorrência de uma perda gestacional. A ruptura temporal pode ser acompanhada por outros tipos de rupturas, como a ruptura do laço afetivo semiótico com outro significativo, como, por exemplo, de uma mulher com o seu bebê natimorto. Ruptura que "[...] se situa [...] no espaço imaterial de um poderoso laço de amor” (Násio, 2007, p. 31) (ruptura afetiva semiótica).

Tempo 2: Há a emergência de um tumulto interno desencadeado pela ruptura. Rupturas externas provocam rupturas internas relacionadas ao sentido do self, ameaçando certo senso de continuidade e de identidade: sentidos acerca de quem se era, de quem se é, e de quem será. A ampliação da incerteza face ao futuro que pode abalar as pontes de sentido constantemente construídas pelos indivíduos entre o passado, presente e futuro. (Abbey \& Valsiner, 2004) A autopercepção do transtorno interno gerado pela ruptura que pode suscitar sofrimento interior e desorientação mental.

Tempo 3: Há a reação defensiva do self para proteger-se do tumulto interno causado pela ruptura, a fim de resgatar um senso de integridade. O self enquanto um intérprete produz esforços na tentativa de traduzir as rupturas em termos simbólicos, conectando os fragmentos da trajetória de vida subitamente interrompida. O self luta para se reencontrar, para se reerguer e, para isso, reúne suas forças com o propósito de autorreparação, lançando mão de estratégias semióticas de reparação dinâmica, criando e fazendo uso de uma miríade de signos (signos reparadores), que podem ser sobrepostos, com o propósito de reparar a conexão entre o passado e o presente, construindo um sentido de futuro possível.

Em suma, quando uma mulher experiencia uma perda gestacional involuntária - uma ruptura significativa que não era esperada aconte- 
cer - faz-se necessário que algum significado generalizado, ainda que provisório, seja construído para fornecer uma síntese, unidade e alívio. No entanto, pode-se argumentar que a experiência recorrente de rupturas significativas requer um tipo particular de processo semiótico - as estratégias semióticas de reparação dinâmica do self. Estas estratégias, ao serem utilizadas, levam à construção de signos específicos - os signos reparadores -, que têm o poder de realizar algum tipo de conexão dos fragmentos da trajetória interrompida, construindo alguma articulação entre esses fragmentos e resgatando certo senso de continuidade. Entretanto, o esforço empreendido pelas mulheres em construir os signos reparadores exige tempo. Tempo que corresponde ao período de transição não normativa ou, mais especificamente nesse caso, ao processo de luto - um processo afetivo-semiótico de reparação desencadeado após a ocorrência de uma ruptura e perda significativa no curso de vida, como é o caso das perdas gestacionais involuntárias.

\section{Signos reparadores}

Com base no Modelo de Equifinalidade de Trajetórias (Sato, et al., 2012; Sato, Hidaka, \& Fukuda, 2009), a percepção de que uma mulher está grávida fornece a base para a emergência de uma nova trajetória na qual algo é esperado e está na iminência de acontecer: ter um filho e tornar-se mãe. No caso das mulheres com perdas gestacionais recorrentes, esta expectativa é violada, repetidas vezes, pela realização de outra trajetória marcada pela perda gestacional e perda da maternidade. A trajetória reprodutiva dessas mulheres, assim, sofre importantes rupturas ao longo do tempo, tornando-se descontínua e fragmentada. A fim de restabelecer a continuidade, é preciso que os seus fragmentos sejam novamente conectados, "amarrados" uns aos outros - promovendo a reparação do sistema de significados do self. Esta é a função do signo que denominamos de signo reparador - que precisa ser construído, inventado e utilizado pelo self, através do envolvimento da pessoa em diferentes esferas contextuais da vida após rupturas significativas e recorrentes. 
Os signos reparadores operam sobre as rupturas sucessivas no curso de vida e promovem a emergência de novos significados no momento presente, a reconstrução de significados atribuídos às experiências no passado (perdas gestacionais prévias) e nova orientação para a gama aceitável de construções de significados orientados para o futuro, conectando passado e futuro no presente. Relançando-os em uma nova narrativa, sempre singular - e, de certo modo, unificada e coerente - acerca de si mesmo, da sua própria vida e do seu próprio "destino".

As Figuras 20 e 21 consistem em uma tentativa de representação geral/abstrata do processo através do qual operam as estratégias de reparação dinâmica do self ao longo do tempo irreversível.

Figura 20 - Estratégias de reparação dinâmica do self e emergência do signo reparador

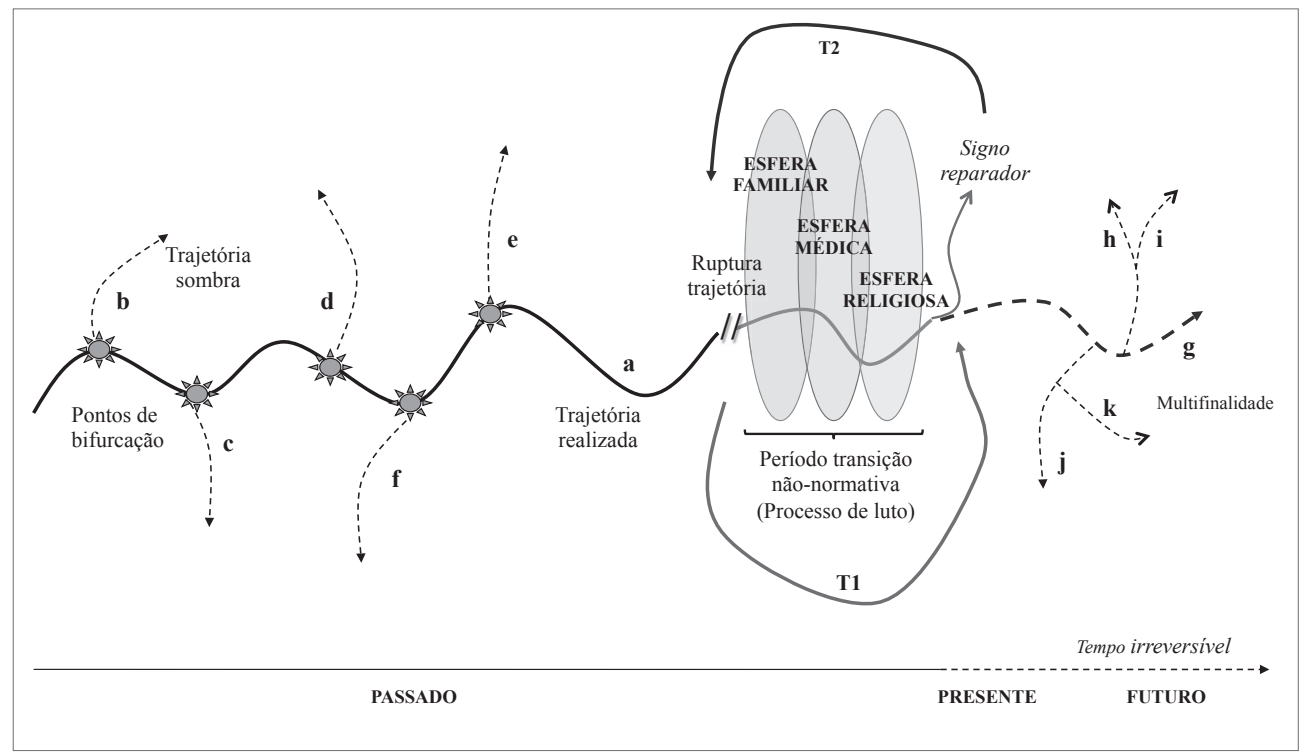

Fonte: elaboração da autora. 
Figura 21 - Conexão dos fragmentos da trajetória interrompida pelo signo reparador

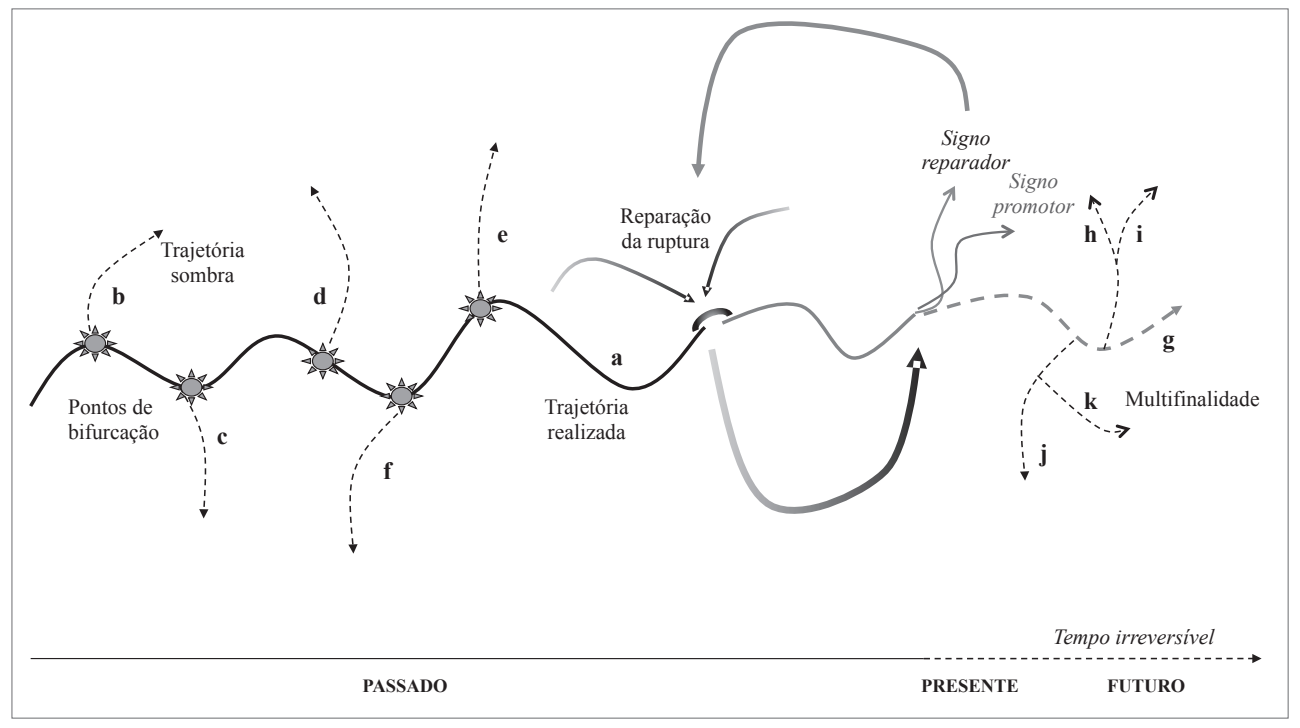

Fonte: elaboração da autora.

Faz-se importante observar, porém, que o esforço de reparação não visa o equilíbrio - no sentido de automanutenção, um retorno ao que era antes, a conservação do status quo -, mas, a autorregulação do self, a partir da emergência de novas estruturas, da emergência de novidade. Deste modo, pode-se considerar esses signos de reparação semiótica como conectores, sejam eles flexíveis - permitindo certa maleabilidade das trajetórias - ou rígidos.

O processo de construção dos signos reparadores pode ocorrer de dois modos: o primeiro, através da internalização de um signo proveniente de alguma esfera da vida (como a esfera médica ou religiosa) na qual a pessoa encontra-se inserida. Isto permite a regulação direta e inquestionável de todo sistema psicológico. O segundo modo de construção dos signos reparadores pode ocorrer através do processo denominado "bricolagem". O termo "bricolagem" foi introduzido por Zittoun et al. (2013) para se referir à auto-organização do sistema de acordo com as demandas da situação e sem planejamento prévio. Consiste em uma montagem flexível 
sintonizada às especificidades da situação, na medida em que utiliza os recursos simbólicos disponíveis naquele tempo e espaço particular. Por tratar-se de uma invenção humana, envolve criatividade e imaginação. Através da bricolagem, um mosaico de diferentes significados pode ser construído e integrado um ao outro - a partir do uso de distintos recursos simbólicos disponíveis no momento e contexto específico, em combinação com a experiência prévia da pessoa -, podendo funcionar como um signo reparador.

Os signos reparadores podem apresentar diferentes níveis de generalidade e abstração, isto é, ser do tipo ponto ou do tipo campo. Os signos do tipo ponto são representações homogêneas e estáveis de algo, como uma palavra (por exemplo, as palavras médicas alteração aloimune e autoimune como explicação para a causa dos abortos espontâneos). Os signos do tipo campo, por sua vez, codificam a experiência pessoal, intra e interpsicológica, sem limites definidos, sempre flutuante, a partir de um complexo semiótico. Logo, são representações abstratas da natureza holística de um fenômeno (por exemplo, quando se diz que uma mulher está de luto após a perda de um bebê). (Valsiner, 2005, 2012; Cabell, 2010)

Vale ressaltar que com a repetição de eventos disruptivos ao longo do tempo - isto é, com a repetição das perdas gestacionais - o self precisa construir signos reparadores cada vez mais complexos e "poderosos" pertencentes a níveis hierárquicos mais elevados de regulação semiótica - como aqueles relacionados aos afetos, aos valores pessoais. Ou seja, faz-se necessário recorrer a um controle dinâmico crescente na regulação semiótica a fim de conseguir integrar a experiência passada (perda gestacional) e seguir em direção ao futuro. Afinal, a restauração da conexão dos fragmentos torna-se uma tarefa cada vez mais difícil e complexa. Pois, o impacto de uma nova ruptura na trajetória pode implicar no reaparecimento de antigas fissuras, exigindo novas reparações a fim de restabelecer a continuidade. Assim, um novo signo reparador precisa ser construído, inventado pelo self, um signo "poderoso" hipergeneralizado, carregado de afeto. Daí a busca por signos promotores nas diferentes esferas da vida e, em especial, naquelas esferas que, na nossa cultura, 
são percebidas como capazes de oferecer respostas/significados aos mais diversos dilemas da vida: a ciência e a religião.

Outro aspecto interessante das trajetórias de vida marcadas por tantas descontinuidades e mudanças consiste no intenso esforço empreendido pelas mulheres investigadas no sentido de manter certa coerência no sistema de significados do self ao longo do tempo. Nesse sentido, houve a construção e reconstrução constante de continuidade, a partir da criação ininterrupta e abundante de signos. Assim sendo, a experiência de rupturas significativas e sucessivas - comum aos casos de perdas gestacionais recorrentes - ilustra que até em situações extremas o self busca reparação. E isto se dá através da criação de signos reparadores, mas também por meio da transformação desses signos, da sua reconfiguração e plasticidade ao longo do tempo irreversível. Um exemplo dessa transformação do signo nos casos analisados consistiu nas modificações constantes da noção de maternidade ao longo das trajetórias reprodutivas, que aparece cada vez mais idealizada após cada experiência de gravidez-perda gestacional, alcançando níveis cada vez mais abstratos de generalização. Houve, assim, uma transformação estratégica do signo reparador em uma exaustiva tentativa de autorreparação e manutenção da estabilidade dinâmica do self, para níveis hierárquicos cada vez mais complexo e abstratos. 